\title{
RURAL TOURISM: A WEBGIS TOOL FOR THE RURAL RESOURCES OF THE APPENNINO LUCANO - VAL D'AGRI LAGONEGRESE NATIONAL PARK, ITALY
}

\author{
ANGELO BENCIVENGA, ANNAMARIA GIAMPIETRO \& ANNALISA PERCOCO \\ Fondazione Eni Enrico Mattei, Italy
}

\begin{abstract}
Rural tourism is characterized by a particularly strong link between the services and territory offer, because the quality of the environmental, social and cultural components of the territory does not represent a background cover, but it is essential to the qualification of the assets. The rural tourism is, in fact, directly connected to what are called "resources of rurality": according to the most widely accepted definition, it is a set of resources which, in addition to those of agriculture and processing of its products, it comprises also cultural and artistic components in rural areas. These resources are classified in terms of rural territorial capital, a cross-along, dynamic and evolving environment that includes the human, cultural, economic, social, institutional and symbolic capital of a particular rural area. The phase of territorial diagnosis is crucial to identify those resources that may represent the rural tourism offer and to help increase the competitiveness of the territory. For this purpose, the final output of this research is the construction of a webGis, an extraordinary geographic information management tool, that offers tourists a complete information system appropriate to their needs.
\end{abstract}

Keywords: rural tourism, rural tourism product, resources of rurality, local development, geographic information system, webGis.

\section{INTRODUCTION}

As part of a rural development policy based on sustainability and the preservation of the vitality of rural communities, tourism becomes an important driver of local development in rural areas, especially if it is coherently integrated in such sector as agriculture, crafts and services. Since rural areas are no longer a homogeneous geographic context, the territorial usability is different in every place, as demonstrated by the wide range of activities included in the rural tourism offer, as the practice of outdoor sports, for example, the local products tasting and participation in events or visits [1].

Rural tourism is characterized by a particularly strong link between the services and territory offer, because the quality of the environmental, social and cultural components of the territory does not represent a background cover, but it's essential to the qualification of the assets [1]. The rural tourism is, in fact, directly connected to what are called "resources of rurality": according to the most widely accepted definition, it is a set of resources which, in addition to those of agriculture and processing of its products, it comprises also cultural and artistic components in rural areas. These resources are classified in terms of "rural territorial capital", a cross-along, dynamic and evolving environment that includes the human, cultural, economic, social, institutional and symbolic capital of a particular rural area.

The phase of territorial diagnosis is crucial to identify those resources that may represent the rural tourism offer and to help to increase the competitiveness of the territory. The offer of rural tourism is therefore made up of a plurality of actors, by a set of resources, some of which are generic and other are specific of the local rural heritage, through the exercise of activities as the production and sale of one or more touristic and recreational services [1]: accommodation, tourist resources, events, infrastructure. 
It appears, thus, the territorial dimension of the rural tourism product so that the use of the term "product-territory" has gradually spread, as a set of inter-sectoral components: the tourism product is made up by the territory as a whole, by its natural and artificial attractions and its usability is often run by local multiple parties. In this context, to compete with each other are no longer the businesses but territories, aiming to attract residents with high purchasing power, investment and tourists. It is therefore crucial that the development of tourism in rural areas is closely related to local spatial in order to adequately enhance the resources of the rural context and its production and to keep alive the local economic and social vitality.

Ever increasing areas are no longer competitive in the agricultural production, so it is recognized the need to diversify their economy by adapting the resources to new uses such as, for example, tourism. For these areas usually excluded from the tourists, offering a quality rural tourism is, in fact, a development opportunity, thanks to the many benefits it can bring in terms of economic, social, cultural and environmental development.

The research aims to develop strategic and operational support tools in the rural tourism sector. For the construction of the tourism product, a diagnostic phase has become essential to assess the tourism potential of the area covered by the study, the Apennino Lucano - Val d'Agri Lagonegrese National Park, located in the south of Italy within Basilicata region.

The final output of this project is the construction of a webGis, an extraordinary geographic information management tool, that offers tourists a complete information system and appropriate to their needs. It is also beneficial to the population, public policymakers and private actors in order to promote the knowledge of the nature, of cultural and social resources and to allow maximization of them for tourism purposes.

\section{SUSTAINABLE COMPETITIVENESS}

The tourism industry is a growing sector due to increasing number of people moving around the world to enjoy their free time. According to the World Tourism Organization (UNWTO), in 2016 international arrivals totalled 1.2 billion. Europe is the most visited area in the world with 615 million arrivals. It should also be stressed that the sector has grown for six consecutive years since 2009 .

While tourism demand is increasing, it is equally true that the tourist destinations are increasing. Besides mature destinations, we find new and different destinations on the market that make it highly competitive. In the recent past, the competitiveness of a destination was evaluated almost exclusively in economic terms but, given the complex nature of tourism, it follows that the ability to compete also resides on other important factors, such as social, culture, politics, technological and environmental dimension.

Ritchie and Crouch [2] describing the terms in which the concept of competitiveness of a destination has changed, explaining how, from a purely economic assessment it was passed to one in which even the environmental dimension takes on weight, arguing that the environmental integrity of a destination represents an increasingly important criterion of choice for holidays.

They suggest to those involved in the management of tourist destinations that the concept of competitiveness in the future will be closely linked to the concept of sustainability and a tourist destination will also rely on an offer based on sustainable tourism. The most recent initiative in terms of commitment to sustainability is the Global Agenda for Sustainable Development with its 17 Sustainable Development Goals, adopted by the UN on 25 September 2015. The agenda expressed a clear opinion on the unsustainability of the current development model, not only on the environmental level, but also on the economic and social one. The innovative aspect of the Agenda is represented by the idea that sustainability is not 
just an environmental issue but an integrated vision of the different dimensions of development. Within the Agenda, tourism can be inserted directly into 3 of the 17 objectives:

- Goal 8, targets: By 2030, devise and implement policies to promote sustainable tourism that creates jobs and promotes local culture and products;

- Goal 12, targets: Develop and implement tools to monitor sustainable development impacts for sustainable tourism that creates jobs and promotes local culture and products;

- Goal 14, targets: By 2030, increase the economic benefits to Small Island developing States and least developed countries from the sustainable use of marine resources, including through sustainable management of fisheries, aquaculture and tourism.

\section{RURAL TOURISM: FROM THE FARM TO THE EXPERIENCE OF RURALITY}

For the purpose of our work it is important to try to give a precise definition of rural tourism which then allows us to identify the related demand and consequently a tourist offer more in line with it.

Tourism linked to rural areas is a type of tourism that, for several reasons including the increasing attention to sustainable tourism, has had a growing interest from institutions, but it is difficult to place within clear boundaries, being it a complex and evolving product.

The phenomenon of tourism in rural areas is the subject of great attention from the media and consumers, a significant quantitative growth and at the same time of profound and rapid changes. It is very complex and articulated in its interior, and this is reflected in a considerable confusion not only from the semantic point of view but also in the identification of ongoing phenomena.

The term rural tourism is currently used not only in publicity and journalism, but even among experts, however without an unambiguous and universally accepted definition, as indeed there is no a clear definition of the basic concept of rurality which should obviously underpin other more sectorial definitions [3].

For our purposes, we consider the definition of rural tourism adopted by the OECD in 1994 [4] which is very close to that found in the most recent community programming instruments in the field, such as the LEADER programs. Rural tourism cannot be defined only by the type of holiday. In this type of tourism also enter other considerations such as the intensity of use, location, style of management, integration with the community, and other factors still play an important role in the definition. According to the OECD rural tourism should:

- Be located in rural areas;

- Be built on the rural characteristics consists of small businesses, open spaces, characterized by contact with nature and the natural world, with the heritage, society and traditional practices;

- Be in the rural dimension, both in terms of construction and organization, therefore, being of small size;

- Be traditional in aspect, it should grow in a gradual and systematic way and connected with local families. Usually it should be locally controlled and managed in order to ensure the wellbeing of the area for a long time;

- Be composed of different aspects in order to represent the varied pattern formed by the rural landscape, the rural economy, rural history and the same rural area.

Based on these features and other definitions such as that of the European Commission, we can say that rural tourism encompasses all those activities implemented in rural areas. 
So, what is rural tourism? OECD compiles a list of activities that usually are considered rural tourism: walking, climbing, adventure holidays, rafting, canoeing, cross-country skiing, snow shoeing, downhill skiing with low impact, the study of nature outdoors, hunting, cycling and cycle tourism, the 'riding, the contemplation of the landscape, the rural heritage studies, visiting countries, relaxing holiday in rural areas, small size conferences, rural festivals, fishing activity along the rivers and channels, sports activities that require natural environments. Rural tourism encompasses much broader contents like nature, ecotourism, rural tourism, adventure tourism, wine and food tourism for which it is difficult to get accurate statistics. Finally, we have taken into consideration the regional law on rural tourism in order to have a clearer regulatory framework.

\section{THE TOURISM DEMAND OF THE AREA}

If we consider the behaviours and motivations of demand within the area of Apennino Lucano - Val d'Agri Lagonegrese National Park, we can define the demand as a particular variation of the cultural tourism, represented by the cultural tourism of the landscape or by the territory discover and very close to the definition of rural tourism. It is a niche tourism based on the enjoyment of the landscape as a bearer of meanings, its motivation is not given by the individual attractors, but rather from the set of environmental, socio-economic, cultural aspects that identify and distinguish a specific area.

The discovery tourism is a form of itinerant tourism hub, since tourists visit a number of points of interest within a circuit. It is generally self-organized and touches predominantly or exclusively minor art centres, or in any case, with contemporary urbanization characters not obvious and "agro-eco-landscapes" (landscapes in which the biological and cultural evolution have suffered a co-evolutionary process, adapting to each other). The entire visit is related to the enjoyment of different aspects and experiences of the territory, from food to art, from craft to natural park [5].

Comparing the significance of discovery tourism with previously described rural tourism, we note that the two definitions are contiguous.

Very interesting and indicative for the creation of a rural tourism product is knowledge of motivations of the tourist demand, for this purpose were collected data through a survey to the tourist within the area with the aim of obtain qualitative information on the motivations, activities experienced, and the places visited during their stay. So together with the choice of nature, tourists spend time visiting relatives and friends, enjoying leisure, entertainment and cultural visit, tasting of typical products, visiting places of production and discovering the traditions [6] (Fig. 1).

It is also essential to get an idea of how the image of the area is perceived by tourists in the digital world. For this purpose, an iconographic analysis of the photos was conducted of those posted on the web by park institution and those posted by tourists. The analysis of the photos posted by tourists shows that the overriding picture perceived is the naturalistic one [6] (Fig. 2). This perception could be due to the absence of a tourist offer based on other resources, we therefore think that the image of the park could be modified thanks to the creation of a rural tourism product built on the other existing resources.

\section{THE TOURISM OFFER OF THE AREA}

The Apennino Lucano - Val d'Agri Lagonegrese National Park, located in the south of Italy within Basilicata region, was established in December 2007 and it is the youngest protected area of Italy. The offices of the Park are located in Marsico Nuovo, in the province of Potenza and includes about 69,000 ha of land, divided into four geographical areas including 29 municipalities: Alta Val d'Agri, Val Camastra, the Alta Valle Melandro and Lagonegro. 


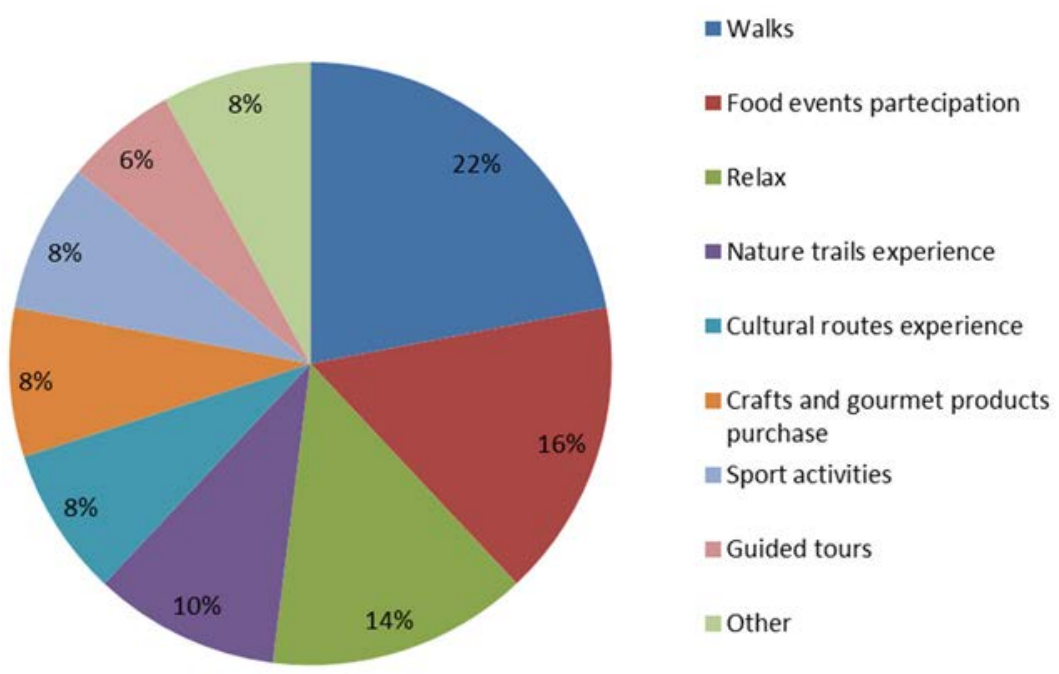

Figure 1: Tourist motivations.

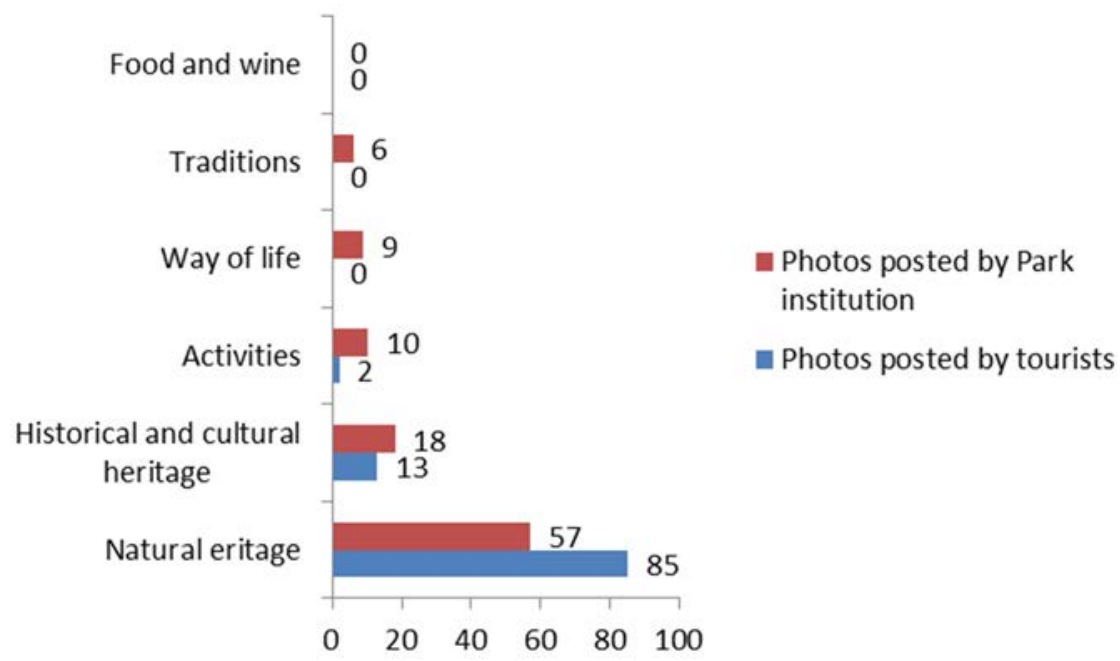

Figure 2: Theme of the photos posted on the web.

According to the literature, various elements compose the tourist offer of a destination, it springs from the combination of tourist attractions and tourist industry, where tourist industry means all those services that make accessible these attractions and, at the same time, facilitate the stay of tourists on territory chosen for vacation. The attractions are the primary and essential elements of the product, including the natural, cultural, events and everything that can be attractive to tourist demand.

In the tourism industry we have the accommodation (hotel, bed \& breakfasts, cottages), catering, reception and fruition services (tourist information centres, services of local guides etc.), accessibility and local transportation systems. 
The selection of resources of the area, which we believe are the most relevant and ready for tourist consumption, which will be discussed in depth in the next chapter, is made through criteria such as location, its state of preservation, the uniqueness and the usability degree.

To get a first idea of the composition of tourism resources of the area, a semantic analysis of the official tourist guidebook of the park and its official site was done. The identified resources have been divided into categories such as natural resources, cultural ones, gastronomy resources, heritage resources. All these resources become interesting in order to build a rural tourism offer (Fig. 3).

By analysing one of the basic service in the tourism industry that is the accommodation, it follows that in the area there are 39 hotels, with a total of 2,415 beds. They are divided between hotels of one, two, three, and four stars with the complete absence of five star hotels. The other forms of accommodation are 78, divided in accommodation run in the form of enterprise, cottages and bed and breakfast for a total of 757 beds. The hostels, the holiday homes and the shelters are absent.

Deepening the analysis of the park official websites we notice that they show information about the tourist resources of the park, the presence of some routes, some existing services, but we do not see any structured tourism product, which may be experienced or even purchased. This can be seen especially in the official tourism website called In vacanza nei Parchi, which looks like a coordinated offer of sustainable and quality tourism.

Two apps are dedicated to the protected area, they are Park Val d'Agri App and Parco Apennino di Basilicata App that provide information on some resources and services in the area. The first available for Android and IOS device divides the information into two sections, a call paths that encompasses thirteen trails with a map, route description and reporting of travel time and difficulty, the other called places of interest that provides the description the municipalities of the park with its points of interest to visit. The second one, only available for Android devices, is divided into sections with information about the natural resources of the park, the lodging facilities, and the description of four itineraries divided between north area and south area. It seems that, within digital tools such as websites and mobile apps, there are only partial information.

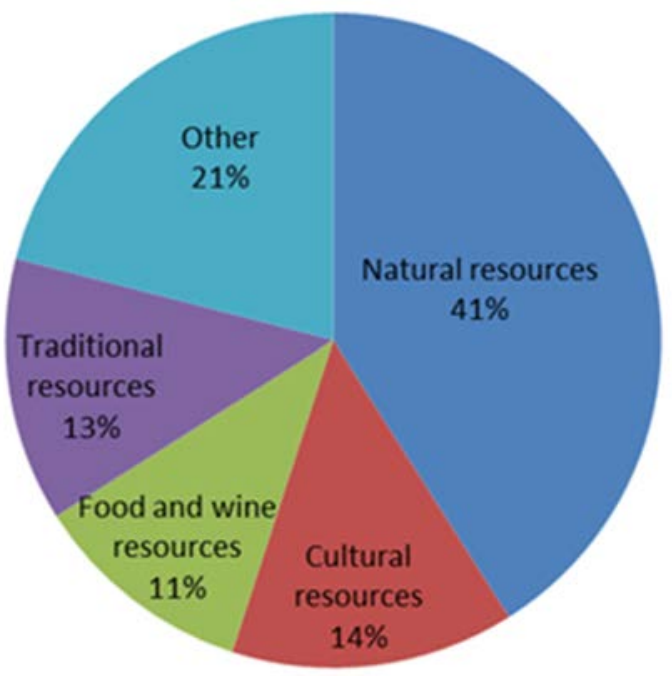

Figure 3: Park's tourist resources. 
To innovate the product creation process is, however, essential to act with a strategy of co-design, it is important to reflect on the territory of all the resources they have in place and on the set of companies that work in it. There is a close relationship between local marketing and relationship marketing. The tourist offer heart is less and less sufficient to meet the changing tourists needs and increasingly oriented towards integrated services. It is essential to operate in a systemic approach to increase the tourist attractiveness of the destinations [7]. The logic behind the idea of the webGis, which we'll discuss in the next section, starts from the knowledge of all the tourism resources and existing services across the country to turn them into tourist products with a value proposition recognized by the market.

\section{THE WEBGIS: A TOOL FOR THE DEVELOPMENT OF RURAL TOURISM}

Thanks to new technologies, in recent years, geographic information has proven to be a key component in the decision-making activities. This importance has not only been highlighted by those people who are responsible for planning and development of a territory, but also from those other actors for whom the knowledge of a given area, its characteristics and its dynamics are a strategic asset to improve the competitiveness. Digitization has given a significant contribution in the use of geographic information, allowing to combine them with all other aspects of social, political, economic sphere, that may be useful in decision-making process.

Through the use of Geographic Information Systems (GIS) you can integrate digital maps with tabular data. Defined as the complex of human resources, tools and procedures that allow to capture and distribute data in an organization, and make them available when they are required to those who need to perform any activity [8], this system has led to associate the typical operations of a database (data storage and warehousing, research and statistical analysis) facilitating interpretation by displaying the map. In this way the area is represented as a set of simple geometric elements used to represent the shape and the position of actually existing elements on the territory (roads, buildings, house numbers, etc.), which are associated with the information that they concern them. The use of this tool in all activities of analysis, planning and management of territorial information offers the ability to view spatial data at different scales of representation, to manage a huge amount of environmental information and lastly, but perhaps the most importantly, it allows to use the GIS representation potential to involve stakeholders in decision-making by showing them results, and future alternative scenarios. At the same time, it is a great tool for archiving actions, processing and analysing a huge amount of data related to all the elements of the territory that have "geo-graphic" characteristics or referred to any place on the planet that can be effectively represented graphically on digital cartography.

The tourism as highly informative activities, has been strongly affected by the development of these new technologies, so it can consider GIS as a new tourist development tools of an area. The integration of the tourist map with other territorial aspects (infrastructure, transport networks etc.) has therefore started to represent a new opportunity for decision makers in this area. The creation, collection, processing and transmission of information are all key issues for the tourist activity that is extremely useful to be able to enter into a single information system all data related to resources (whether historical, architectural, landscape and environmental and gastronomic) and services offered by a particular tourist destination. This makes it very easy to highlight relationships and problems in order to adopt an appropriate tourist planning. In tourist sites, the use of GIS provides users with information relating to accommodation, excursions to be experienced, the places to see, activities, events to attend, to the services in place. This information is geo-localized within a digital geographic map, with which the user can interact, receiving and exchanging 
information online. The need to innovate territories is a topic today which should be given an immediate response, for competitiveness.

Just in that direction, the first result is the agreement between the Government and the Regions for the development of tools and digital infrastructure for tourism in Italy approved on 7 July 2016 within the Standing Conference between state, regions and autonomous provinces of Trento and Bolzano, in which the event digital Ecosystems - Strategies, infrastructure and digital tools for Tourism Destination Italy, held on 2 December 2016. Inside one of the working groups called From Digital to Digital Ecosystems tourism [9], in particular the shared is building accessible databases between the various local actors, with indications of accessibility and identification of sharing standards (for example, information geo localization and classification of structures).

As mentioned, the design of a webGis appears as an extremely useful tool to apply to the Appennino Lucano - Val d'Agri Lagonegrese National Park, which is rich in resources that, when integrated with existing services, they can be the basis for the construction of a tourism product that meets the demand for rural tourism. The objective of this work is the creation of a webGis as planning and territorial development tool, oriented to both the managing body of the area, both to tourists interested in exploring the product/territory, and also to citizens who would like to invest in the territory, but often do not possess the information needed to invest.

The system aims to be an instrument of knowledge of the area, which could support the socio-economic development of facilitating relations between the government, businesses and citizens in view of a territorial marketing logic. The project started as a selection and integration of very heterogeneous spatial information. The collected data were grouped into eleven thematic areas: Paths; Food Resources; Natural Resources SACs (special areas for conservation); Natural resources SPAs (special protection areas); Religious Resources; Cultural Resources; Educational Farms; Environmental Education Centres (CEAS); Dining Facilities; Travel Agencies and Tour Operators; and Events.

The data were collected by the identification of multiple sources, such as internal research reports, the open data web site of Basilicata region, the territorial promotion agency of Basilicata, official lists of existing tourist services from Basilicata region, The Ministry of the Environment and Protection of Land and Sea of Italy web site, free private source, the official websites of Appennino Lucano - Val d'Agri Lagonegrese National Park.

The value of this work is given by having collected and standardized into a single digital platform all useful data for the creation of the product/territory and have made them accessible, through its integration into any website.

The creation of the webGis and related information represents the starting point of a future process that, according to our intentions, will lead to the increase of the information contained in it, through the involvement and contribution of all those interested in the development of the area for tourist. In fact, the idea is to start a crowd-mapping process (maps produced by users and citizens) by inviting all interested parties to indicate those resources and those services useful to the creation of a product/territory linked to rural tourism. By way of example, here are some images extrapolated from the constructed webGis (Figs 4 and 5).

\section{CONCLUSION}

The study has highlighted the potential related to the use of information and communications technology as support for regional marketing and tourism promotion policies. In particular, the research analysed, the usefulness of a webGis for the construction of a rural tourism product in the Apennino Lucano - Val d'Agri Lagonegrese National Park, located in the south 


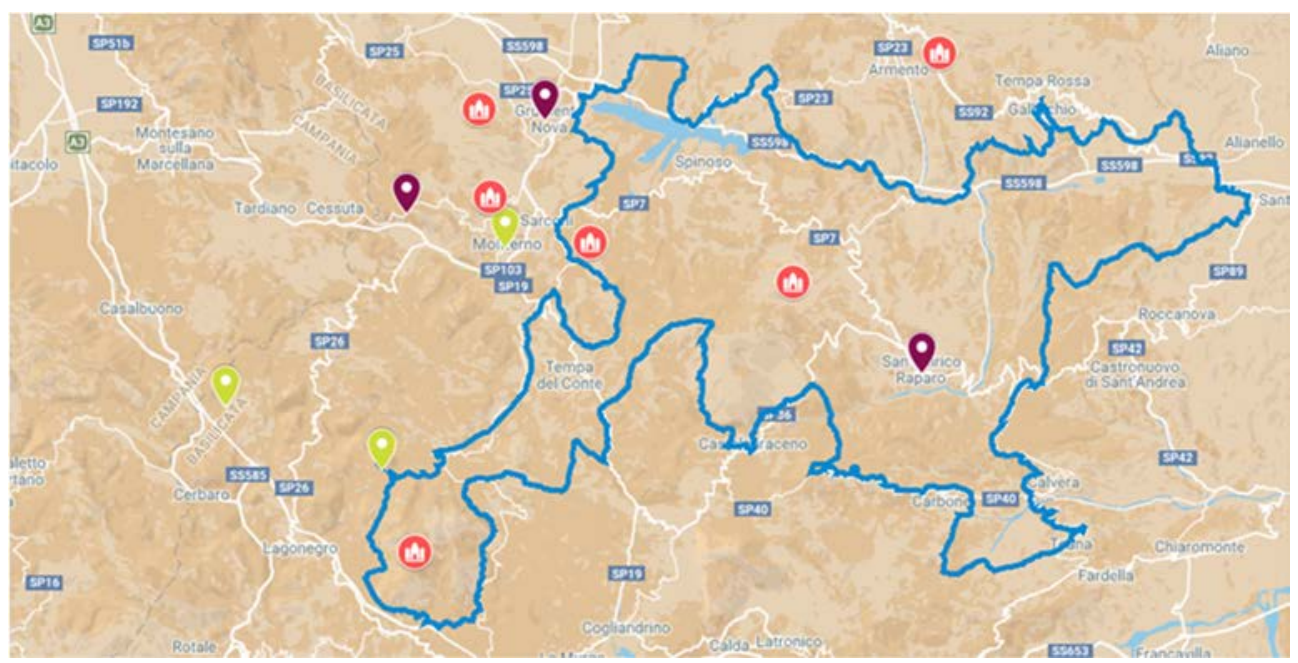

Figure 4: Screenshot webGis.

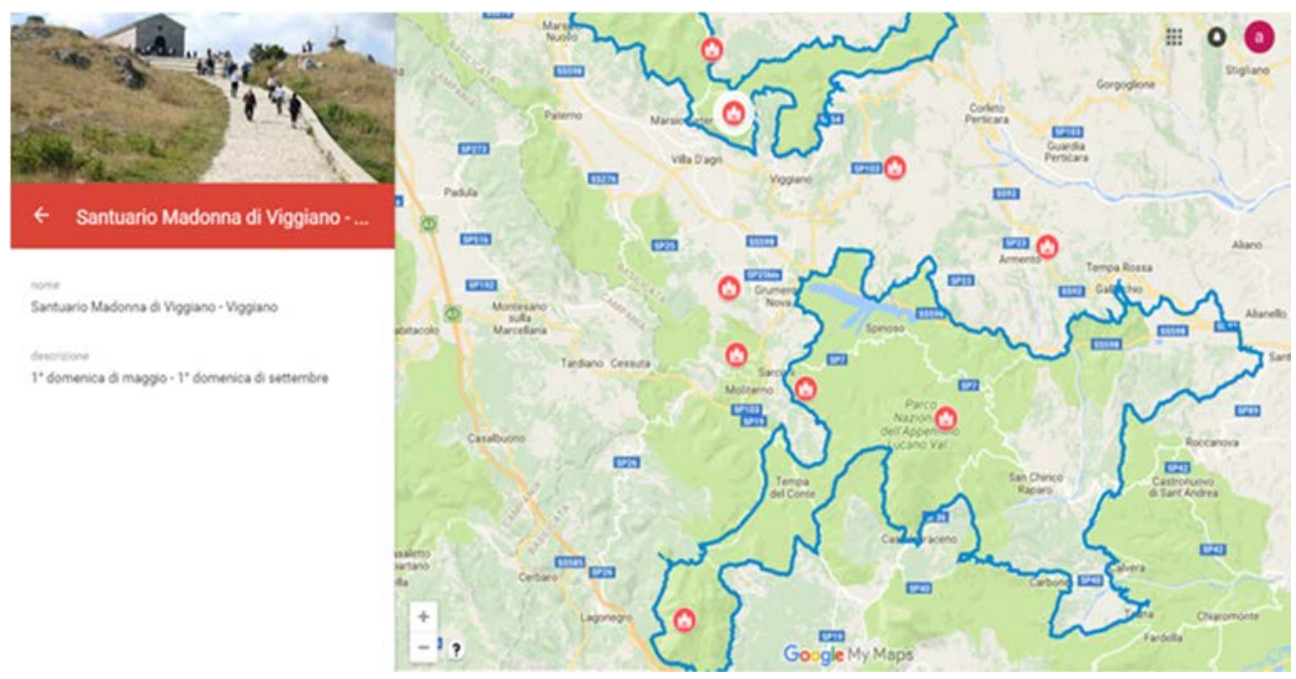

Figure 5: Screenshot webGis.

of Italy within Basilicata region. In particular, the webGis can pursue several objectives simultaneously:

- $\quad$ supplementing and updating the geographic information of tourist interest;

- promoting the knowledge in the local community of the tourist potential of the area;

- providing tourists one convenient tool for gathering information, through simple consultation of digital map;

- networking services and tourist resources of the area for tourists, thanks to the technological support. 
The study was completed with the testing of a webGis as a tourist product that facilitates relationships between the firms, traders, local community and tourists. The product was made using a webGis platform which allows a high level of interaction between the map and the tourist who can select the information to display. This map, that is implementable on the basis of any requirements of the managing body of the national park can be integrated also into web pages of any site linked to the promotion of the protected area. GIS technology integrates information with different subjects, implying, therefore, a sharing ideas and strategies for the promotion of a territory. The critical reading and the possible conclusions of this study confirm and recognize the tourist potential of the area covered by the research and recognize the webGis as an important and dynamic tool that can be out scaled at any time to analyse, plan and implement local marketing activities. The solutions can, therefore, be a good starting point for the national park management for the distribution of its tourist information and promotion of its territory and sustainable tourism, with innovative and attractive mean. The webGis could be used as a starting point to build a shared webGis, able to disseminate the different components of the local heritage. The project may include other various implementations.

To increase the interest in the future, you might think of the conveyance system on mobile devices owned by the user (creation of the app), the integration with other tourism management systems (e.g. online booking) that could be used both from single facilities both consortia or associations (such as Tourist Board). Finally, georeferenced webGis information could be used for the construction of a chat app based on artificial intelligence (Bot) to promote and market the tourist offers.

\section{REFERENCES}

[1] Belletti, G., Ruralità e Turismo, Agriregionieuropa, 2010.

[2] Ritchie, J.R.B. \& Crouch, G.I., The Competitive Destination, Cabi Publishing, 2003.

[3] Turismo rurale: azioni di sostegno al femminile per orientare, ricercare, migliorare, attivare una rete di esperienze, www.corintea.it. Accessed on: 17 Nov. 2016.

[4] Organisation for Economic Co-operation and Development, Tourism Strategies and Rural Development, OECD: Paris, 1994.

[5] Fondazione Eni Enrico Mattei \& Ciset, For a Development Project of the National Park Appennino Lucano Val d'Agri Lagonegrese, 2013.

[6] Fondazione Eni Enrico Mattei, Image, Supply and Demand Analysis of Regional and National Protected Areas in Basilicata, Eni Enrico Mattei Foundation, 2014.

[7] Del Baldo, M., Network agreement and tourism: Enterprise collaboration as a driver of competitiveness of the industry and of the territory. An analysis of the first experiences. Journal of the Science of Tourism, 5(1), pp. 71-116, 2014.

[8] Mogorovich, P., Dalla tecnologia alla cultura dell'informazione. Il contributo dei Sistemi Informativi Territoriali, Bollettino d'Informazioni del Centro Ricerche Informatiche per i Beni Culturali, I - Scuola Normale Superiore - Pisa, 1, pp. 113-121, 1991.

[9] Ecosistemi digitali, www.toscanapromozione.it/ecosistemi/. Accessed on: 23 Mar. 2017. 